TRANS · núm. $2 \mathrm{I} \cdot 2017$

DOSIER · 49-62
Desde su publicación en 1605, Don Quijote se ha ido convirtiendo en parte de una cultura global colectiva, al ser traducido y adaptado a numerosas lenguas y contextos sociales. El más reciente paso en la tradición quijotesca es la aparición de videojuegos que supuestamente encuentran inspiración en el clásico cervantino. Estas nuevas remediaciones proporcionan una percepción de los múltiples reflejos del hipotexto, a veces ocultos en el crossover narrativo, o reducidos al uso del nombre del protagonista. Ya estén cerca o lejos del texto seminal, estas nuevas adaptaciones demuestran que el mito quijotesco tiene todavía una fuerte presencia en nuestra cultural global.

PalABRAS Clave: Quijote, presencia, videojuegos, remediación, aplicación.

\title{
Quijobytes: reflejos especulares del mito quijotesco en el ocio electrónico
}

\author{
MIRIAM BORHAM PUYAL \\ Universidad de Salamanca \\ Daniel Escandell Montiel \\ Manchester Metropolitan University
}

\section{Quixobytes: Specular Reflections of the Quixotic Myth in Electronic Leisure}

Since its publication in 1605, Don Quijote has increasingly become part of a collective global culture, being translated and adapted into numerous languages and societies. The most recent step in this quixotic tradition has come in the shape of videogames that allegedly find their inspiration in the Cervantean classic. These new remediations provide an insight into the multiple refractions of the hypotext, sometimes hidden among the crossover of narratives or reduced to the use of the character's name. Whether close or far from the seminal text, these new adaptations prove that the quixotic myth is still a strong presence in our globalized culture.

KEYWORDS: Quixote, presence, video games, remediation, application. 


\section{INTRODUCCIÓN}

Uno de los valores de éxito cultural que hemos atribuido clásicamente a las obras artísticas es cómo su impacto se percibe en las creaciones de artistas posteriores a través de la identificación de las huellas de la misma, por ejemplo, a partir de la intertextualidad en el caso de la literatura. Esta relación entre el hipotexto y sus herederos (la relación intertextual, paratextual, metatextual, hipertextual y architextual) trasciende el campo artístico original, como sabemos, y las artes dialogan entre ellas y amplían las vías de relacionarse y vincularse entre sí. En el caso de los videojuegos, como medio interactivo, ${ }^{\mathrm{I}}$ debemos tener en consideración no solo las opciones de conexión derivadas de su guionización y de su componente audiovisual, sino también el aspecto lúdico ${ }^{2}$ de los mismos como un elemento estructural más del conjunto creativo.

Cuando la vinculación entre diferentes obras conforma el eje fundamental del proceso crea-

I Evitamos aquí el debate espurio sobre si los videojuegos son (o pueden ser) una forma de arte, por anquilosado y considerarlo carente de fondo. Resulta evidente que como medio audiovisual combina múltiples elementos estéticos y tiene capacidad narrativa. Debe añadirse también el componente de la interacción y cómo el usuario interviene sobre el juego de acuerdo a los parámetros definidos por los diseñadores para alcanzar una meta determinada: el factor lúdico, en tantas ocasiones empleado como excusa para desprestigiar todos los componentes artísticos y creativos por neoluditas, no puede en ningún caso desmerecer la suma de sus demás factores estéticos. No solo eso: la ludología ha mostrado ya una evidente relación entre el juego y el arte (Gutiérrez, 20II) y se ha hablado del videojuego como la más sofisticada - hasta el momento- encarnación del concepto wagneriano de la obra de arte total o Gesamtkunstwerk (Riera, 20I3).

2 Se da una relación hipolúdica entre videojuegos, particularmente con aquellos que resultan definidores de géneros, o entre sus propias sagas en relación con cómo se juegan. Así, por ejemplo, un título como Wolfenstein ${ }_{3} D$ (I992) de id Software define la acción en primera persona y se convierte en el modelo a seguir (y evolucionar) en años posteriores por títulos de la misma compañía (como las sagas Doom y Quake), y multitud de competidores de otras empresas, que se apropian del modelo y lo modifican buscando mejorarlo y aportarle rasgos distintivos. tivo los artistas ejercen como remezcladores ${ }^{3} \mathrm{O}$ semionautas, según explica Bourriaud:

«Semionauts» [are those] who produce original pathways through signs. Every work is issued from a script that the artist projects onto culture, considered the framework of a narrative that in turn projects new possible scripts, endlessly. The DJ activates the history of music by copying and pasting together loops of sound, placing recorded products in relation with each other. Artists actively inhabit cultural and social forms. The Internet user may create his or her own site or homepage and constantly reshuffle the information obtained, inventing paths that can be bookmarked and reproduced at will. (2002: 18).

Así, la combinación de elementos aparentemente separados y el unirlos, como se ha hecho en tradiciones como la del mash-up, ${ }^{4}$ el crossover $^{5}$

3 Fernández Porta (2008) desarrolla el concepto del sample en el arte retomando la metáfora del DJ empleada ya por Bourriaud y sitúa la remezcla en el centro de la práctica artística y creativa como rasgo distintivo.

4 Aunque nace en la música como la combinación no intermedial de diferentes temas musical —en una suerte de collage sonoro-, la etiqueta se emplea ya de forma habitual en otras obras y textos en las que se integran elementos novedosos en una obra ya establecida, como por ejemplo en la conocida Pride and Prejudice and Zombies (Austen \& Grahame-Smith, 2009), donde el universo de la fantasía de los zombis se integra en la novela original de Austen en un proceso de reescritura. El éxito inmediato de esta novela dio lugar a la reescritura de muchos otros clásicos, que, en su mayoría, respetaban la mayor parte del hipotexto y aportaban pasajes claramente imbuidos de los nuevos lugares comunes de la literatura zombi o vampírica. De la literatura, el concepto de mash-up pasó a la historia, dando lugar a pseudobiografías como la conocida Abraham Lincoln Vampire Hunter (2010), también obra de Grahame-Smith. Tanto el mash-up de la novela de Austen, como la biografía de Lincoln ya han sido adaptadas al cine. Además, la primera obra de Grahame-Smith ha dado lugar a precuelas, secuelas y videojuegos, creando un universo multimedia nuevo en torno al mash-up y marcando el camino a seguir para el cada vez más popular género literario.

5 Combinación de diferentes personajes o espacios provenientes de universos ficcionales diferentes para crear una nueva historia original que ha dado la mayoría de sus frutos en el cómic, aunque suele señalarse el primer gran 
$y$, en definitiva, el sample, forma parte del arte mainstream tras haber pasado por procesos de experimentación, como en la reciente narrativa española y sus corrientes más arriesgadas (Ferré, 2007: 17). Poca duda cabe de que, cuanto más icónica y disruptiva es una obra, más atención recibe por los creadores que se sienten influidos por ella: en este sentido, el Quijote ha sido uno de los textos más influyentes de la literatura española y su presencia se puede rastrear abundantemente en la literatura universal.

En lo referente a las traducciones, las primeras versiones aparecen en inglés y francés a los pocos años de publicarse la primera parte, pasando después al italiano y al alemán con relativa rapidez. En cuanto a las adaptaciones más creativas, la primera referencia al texto Cervantino aparece en 1606 en la obra de George Wilkins The Miseries of Inforst Marriage, con el uso de la expresión "luchar contra molinos" (Avalle-Arce, 1989: 59), comenzando una larga tradición de reescrituras quijotescas en la literatura inglesa, la cual incluye obras de nombres tan destacados como Henry Fielding, Laurence Sterne, Jane Austen, George Eliot o Graham Greene. En Francia o en Alemania también es posible encontrar dichas adaptaciones a lo largo de los últimos cuatro siglos. Algunos ejemplos incluyen la obra de Charles Sorel $L e$ berger extravagant (1627-28) o Die Abenteuer des Don Sylvio von Rosalba (I764) de Christoph M. Wieland. Cruzando el Atlántico existen textos quijotescos destacados en la literatura norteamericana, como es el caso de Female Quixotism (I8or) de Tabitha Tenney.

uso de esta estrategia en la novela de Mark Twain Adventures of Huckleberry Finn (1884) por la aparición de Tom Sawyer, que había nacido como personaje en 1876. En el ámbito del cómic cabe señalar, por ejemplo, la fusión de universos textuales de DC y Marvel en Amalgam Comics, donde las editoriales crearon un continuo crossover de personajes y contextos.
La figura de su protagonista (y, en menor medida, de su compañero de fatigas, Sancho Panza) ha causado también un gran impacto en el arte y la literatura universales: pintores, escultores y demás artistas visuales han recreado la imagen del caballero de la triste figura en multitud de ocasiones y sus representación física - anciano y desgarbado, con poblada barba canosa y equipado con algún tipo de armadura y el baciyelmo en la cabeza-, es universalmente reconocible gracias a la interpretación del texto cervantino por artistas han desarrollado la representación iconográfica del personaje, ${ }^{6}$ con ejemplos tan diferentes pero significativos como los grabados de Gustave Doré (i863) o la versión en manga de 2009 producida por Kosuke Maruo.7 En estos casos, no solo se recodifica la obra a través de otras artes, sino que el personaje es muchas veces protagonista en solitario, convertido en un referente cultural independiente de la obra que lo vio nacer, tal y como ha sucedido con otros grandes mitos literarios, como el también castellano Don Juan. ${ }^{8}$

6 Especialmente relevantes para entender la naturaleza icónica del personaje son las obras de Edward Riley «Don Quixote: from Text to Icon», Cervantes: Bulletin of the Cervantes Society of America, 8 (1988), I03-15; y José Manuel Lucía Megías, Leer el Quijote en imágenes. Hacia una teoría de los modelos iconográficos (Madrid: Calambur, 2006).

7 Se publicó en 2009 en Japón como parte de la colección Dokuba Manga («leer a través del manga»), centrada en publicar en formato manga clásicos literarios occidentales (literarios, pero también ensayo de todo tipo, incluyendo las obras de Karl Marx y Charles Darwin) para acercarlos a los jóvenes lectores nipones. Esta versión es especialmente conocida por haber sido publicada en español en 20I6, pero en 2013 se publicó en Japón una versión más reciente, ドン・キホーテ 憂い顔の騎士その愛 (Don Quijote Ureigao no kishi sono ai), con guion de Kawata Yushi y dibujo de Yukito, dividida en dos tomos, con una resemantización estética total del personaje: un apuesto Don Quijote y un adolescente Sancho Panza son los protagonistas de esta reinterpretación total del texto cervantino.

8 Ian Watt equipara el mito de Don Quijote al de Fausto o Don Juan y señala el reconocimiento universal de estos mitos (1996: 74-75), aunque Jean Canavaggio señala 
La filosofía del semionauta implica que la obra textual sea el punto de partida en una red sináptica de conceptos que se vinculan con otros para dar lugar a la apropiación, reinvención (y deformación) de la figura del hidalgo, tal y como ha sucedido en las diferentes adaptaciones y reinvenciones que podemos encontrar en la literatura. En el ámbito literario es posible hablar de diversas adaptaciones, más o menos cercanas al original, desde los quijotes literarios que desarrollan el tema cervantino del diálogo entre literatura y vida, ficción y realidad, a los llamados quijotes desplazados o «figuraciones», personajes que «no son don Quijote pero que son como don Quijote» (Pardo, 20Ir: 238). En estos últimos casos el hipotexto es perceptible, aunque se limita a una asimilación superficial de la fórmula quijotesca o al uso de ciertos pasajes fácilmente reconocibles para un público que quizá no haya leído la obra pero que comparta el imaginario colectivo en el que don Quijote se ha convertido en un icono universal o ideologema (Iffland, 1987). ${ }^{9}$ En este sentido, es importante, por la conexión que tendrá el público al que van destinados con los videojuegos y juegos educativos, observar que la adaptación de el Quijote a la literatura infantil $-\mathrm{O}$ a los recursos educati-

que son distintos en que el poder de transformación del personaje cervantino es mayor que el de Fausto o Don Juan, por ejemplo (2005: 326). En cuanto a este último, no deja de ser llamativo que este arquetipo, que se conforma en la tradición literaria española, sea también conocido como Don Giovanni: y es que el personaje, que logró fascinar a literatos como Camus, Byron, Pushkin o Austen, tuvo un importante impacto también en la música gracias a la ópera Don Giovanni (1787) de Mozart con libreto de Lorenzo da Ponte, quien tomó como base el de Bertati: desde luego, suficiente relevancia cultural en el imaginario colectivo como para que el nombre italiano sea comparable en el contexto internacional en reconocimiento con el español.

9 Miriam Borham Puyal ofrece de manera concisa la clasificación de los quijotes de acuerdo a su cercanía o fidelidad la original, distribuyendo las adaptaciones en quijotes literarios, ideológicos y desplazados (2015b: 13-4). vos offline y online - ha seguido ese patrón de simplificación del mito a la caracterización o los episodios que se han convertido en icónicos, muchas veces sacrificando la fidelidad al original en el proceso (Borham-Puyal, 2015a, 2016).

Esta variada asimilación se da también en otras artes, como en el ballet Don Quichote dansé per Mme. Sautenir, remediación ${ }^{\text {Io }}$ coetánea del texto cervantino que se estrenó en Francia en I6I4, las múltiples óperas (firmadas por compositores como Purcell o Mendelssohn), poemas sinfónicos (como el de Richard Strauss), el disco La leyenda de La Mancha de la banda Mägo de $\mathrm{O} z$, sus múltiples adaptaciones al cine (empezando con la perdida versión de la productora Gaumont de 1989), la serie de animación española de 1979 y, justo un año más tarde, una japonesa titulada Don Quijote y los cuentos de La Mancha (1980) (además de versiones más libres, como Don Coyote y Sancho Panda, de la productora estadounidense Hanna-Barbera, emitida en 1990), series de acción real como la de TVE de 1992, e incluso la aparición en tebeos, como Mortadelo de la Mancha, de Francisco Ibáñez (2005). Por tanto, ya en estas remediaciones podemos encontrar importantes aportaciones de los autores responsables del cambio de medio con respecto a la obra de Cervantes y muestran una saludable tradición de la reinvención del hidalgo: los videojuegos no podían ser diferentes.

La imagen que se obtiene a través de estas remediaciones no es la de la obra original, el

ro Empleamos el término en el sentido de reinterpretar la obra mediante el cambio de un medio o soporte, es decir, verter —en este caso, de la palabra escrita - a otro, como el cine. En este sentido, implica ir más allá de la simple adaptación, pues se incorporan muchos elementos novedosos derivados de las necesidades estrictas del cambio de medio (adaptación) y de la creatividad propia de los nuevos autores, que retoman la obra base para generar una obra nueva. Sobre la cuestión terminológica, recomendamos la consulta de Mora (20I4). 
texto de Cervantes, sino un reflejo especular: por mucho que la luz reflejada sea parecida al original, es algo diferente. La luz de la obra puede ser una refracción o llegar a nosotros a través del reflejo deformado: ese es el espacio de variación y recreación que se da al trabajar sobre la pieza seminal.

\section{EL ESPEJO ES LA PANTALLA}

La reciente historia de los videojuegos, iniciada en la segunda mitad del siglo $\mathrm{xx}$, ha generado un espacio suficiente para establecer vínculos con la literatura universal, aunque evidentemente los intereses han variado según la región del mundo. En Japón, por ejemplo, es popular la saga Romance of the Three Kingdoms, ${ }^{\text {II }}$ que se basa en el texto histórico Registros de los Tres Reinos (三國志) de Chen Shou, escrito en el siglo III y que abarca los años I89 a 280 centrándose en el conflicto de los reinos de Wei, Shu y Wu. En Occidente, con el fuerte peso anglosajón en la industria del entretenimiento, no puede extrañarnos que abunden las versiones del ciclo artúrico e incluso adaptaciones de textos como Classic Adventures: The Great Gatsby (2010), ${ }^{12}$ The Adventures of Tom Sawyer

II Pese a que el título internacional parece hacer referencia a la novela homónima del siglo XIV atribuida a Luo Guanzhong que se ambienta en la dinastía Han, no es el texto en el que se inspira la saga de estrategia bélica que ha triunfado en los videojuegos, pues es parte del texto histórico referido y no en esta obra de ficción. Sin embargo, Guanzhong utilizó este texto como fuente de inspiración para su novela, y, puesto que los videojuegos aportan multitud de elementos históricos ficcionales, se sitúan en un plano hipertextual paralelo a la novela de Guanzhong: ambos parten de la crónica de Shou y la ficcionalizan.

I2 Se trata de un juego de localizar objetos. En 20 II se publicó otro juego basado en esta novela: un título independiente con estilo retro inspirado en las posibilidades técnicas de la consola NES de 8 bits de estilo plataformas. Fue creado por Charlie Hoey y Pete Smith.
$(\mathrm{I} 989)^{\mathrm{r} 3} \mathrm{O}$ Fahrenheit $45^{\mathrm{I}}$ (1984), ${ }^{\mathrm{I} 4}$ algunas de ellas tan libres como Dante's Inferno (2010), ${ }^{15}$ una reinterpretación absoluta del texto de Alighieri. Sin embargo, desde nuestro punto de vista, resulta inevitable prestarle atención a La abadía del crimen (1987), videojuego creado por Paco Menéndez, que adaptaba la novela Il nomme della rosa de Umberto Eco, publicada unos años antes, y que se convirtió en todo un clásico de los videojuegos. ${ }^{16}$

En cuanto a la presencia de la literatura española en los videojuegos, esta no es tan destacada como en el caso de otras tradiciones lingüísticas, en buena medida por el condicionante económico-industrial que supone el escaso desarrollo histórico del sector de los videojuegos en España frente a otros países del entorno europeo y el déficit estructural de esta industria también en América Latina frente a EE. UU. y Canadá, dos gigantes del sector del videojuego y que se han centrado en la tradición anglosajona.

Pese a ello, resulta fundamental el año 1987 para la relación entre los videojuegos y la literatura española. Manuel Orcera (programador) y Francis Moragrega (grafista) publicaron en ese año $E l C i d$, videojuego que se lanzó en los

I3 Un plataformas con elementos de fantasía, como un pulpo gigante. La versión occidental cambió el orden de los capítulos del original japonés. Además de este título, SquareSoft publicó Square’s Tom Sawyer ese mismo año: en este caso, un juego de rol con estética manga.

I4 Juego de estrategia para ordenador en el que asumíamos el papel del protagonista de la novela y debíamos evitar a las autoridades. Ray Bradbury colaboró con los desarrolladores y escribió el prólogo y las líneas de diálogo de una inteligencia artificial que aparece en el juego llamada Ray.

I5 Se centra por completo en el infierno y el héroe es un caballero medieval que se enfrenta a todo tipo de demonios para liberar a su amada.

i6 Debemos señalar que, si Eco se basa claramente en Guillermo de Occam para su protagonista, Guillermo de Baskerville, en el videojuego se retoma la identidad de Occam para el mismo. 
ordenadores de 8 bits más importantes de la época (Amstrad CPC, Sinclair ZX Spectrum y MSX). El juego fue distribuido en España por Dro Soft y en el Reino Unido por Mastertronic. Se apostaba en él por una perspectiva isométrica y la acción con control directo sobre el Cid combinando una ambientación de inspiración musulmana-medieval, ${ }^{17}$ con otros mágicos. Pese a la simplicidad de la acción que podía ofrecer el juego, pues como otras producciones de la época se trata de un título fuertemente condicionado por las limitaciones del hardware, el usuario debía encontrar varios objetos (una lámpara que permite atravesar los dominios demoníacos, y un saco de dinero para comprar el último ítem, una llave mágica). En el juego aparece también, aunque con un papel anecdótico, doña Jimena, creando así un dúo de personajes históricos y literarios que forman parte de un universo diferente en el videojuego.

En 1987 es también cuando se publica Don Quijote de Dinamic Software, desarrolladora y editora española que se basa en la serie de animación emitida originalmente entre 1979 y I98I por TVE, lo que marcó su estética y el tono ligero de esta aventura conversacional:

Estos productos lúdicos de software se caracterizan por presentar una interfaz de texto basada en analizadores sintácticos o parsers. De este modo, el jugador interactúa con la propuesta jugable de sus desarrolladores por medio de una serie de comandos verbales que permiten al usuario avanzar a través de los distintos escenarios y avatares diseñados (Martín, 2015: 84-85).

\footnotetext{
r7 Al menos, así es en cuanto al diseño general de los enemigos, que resultan claramente inspirados en los retratos de Saladino y sus tropas tras pasar por el filtro del imaginario cristiano y su arte. Sin embargo, a las tropas musulmanas hay que añadir también enemigos cuyo diseño se basa en los soldados de las Cruzadas, todos ellos decididos a derrotar al Cid para alcanzar su gloria.
}

A través del cambio de formato (videojuego) y la interacción planteada (el usuario lanza instrucciones al programa para indicar acciones), el texto cervantino se convierte en una experiencia lúdica con fuerte peso textual: lo hace, sin embargo, a través de un conjunto de fuentes y no de una fuente única. De hecho, el juego animaba en su manual a leer la obra de Cervantes y ver la serie de animación para comprender y conocer toda la dimensión del personaje: ${ }^{18}$ esto es importante porque la historia del juego está basada en la novela, pero no pretende seguirla. Se aprovecha, por tanto, de novela y personaje, se sustenta en la serie de animación, y desarrolla una nueva versión del personaje. Se retoman elementos populares, como los molinos de viento, la gran biblioteca de la casa de Alonso Quijano, y otra iconografía definida en la serie televisiva, y el jugador se pone en el papel del hidalgo y es guiado por un narrador. El componente de libertad de acción (dentro de las posibilidades del género y la tecnología de esos años) redefine la relación entre receptor y obra, que es un producto derivado en el que el reflejo de don Quijote es especular, sí, pero también difuminado por el proceso de recreación.

Este título de Dinamic, sin embargo, no fue el primero en tomar como fuente de inspiración el personaje cervantino: le precede Super Don Quix-ote de 1984, una recreativa en Laserdisc de Universal al estilo del más conocido Dragon's Lair (I983): 19 vemos una aventura con estilo de dibujo animado norteamericano en el que un joven y rubio caballero llamado Don que monta

I8 Para un análisis pormenorizado de este videojuego y su vinculación con el universo quijotesco, recomendamos el estudio de Martín (2015).

I9 Se trata, en esencia, de un vídeo interactivo: en pantalla se indica en determinados momentos los botones que debe pulsar el jugador. Si pulsa el erróneo o se demora, el vídeo muestra la muerte de personaje; si el jugador acierta, el vídeo sigue reproduciéndose. 
en burro junto a un Sancho lancero que va a pie es atacado por las criaturas aladas que le manda una bruja. Su misión es rescatar a la bella y joven princesa Isabella (su novia) y, para ello, recorre incluso las pirámides de Egipto. De hecho, uno de los pocos paralelismos con la obra original es el momento en el que Don se enfrenta a un gigante en un molino (en concreto, a un gigante que retoma el imaginario del nubio con cimitarra en un molino que recuerda a la iconografía de la torre de Babel); el resto, es el personaje enfrentándose a espadazos contra demonios, serpientes gigantes, esqueletos, momias y dragones.

En la época se pusieron ya en duda las razones por las que se empleó el nombre del personaje de Cervantes debido a la escasa vinculación con la obra: "presumably the story line is based on Cervantes' famous novel of Don Quixote and his faithful companion, Sancho Panza» (CVG, I985), y es que la ambientación es de fantasía medieval con toques exóticos y el único personaje que podemos identificar claramente es en realidad Sancho, pues se corresponde con la descripción física del personaje y en sus breves apariciones (huye cuando empiezan los peligros) intuimos también su personalidad.

Super Don Quix-ote hace del hidalgo una excusa de la que no aprovecha la iconografía ya existente, salvo en el caso de Sancho (aun así, con matices): ni siquiera el nombre es explotado más allá del título, pues el personaje es solo referido como «Don» (por Isabella) o «señor Don» (por Sancho). Este tipo de explotación del nombre, como la apropiación y aprovechamiento de una marca, nos recuerda al fenómeno (que se dio en los primeros años del nacimiento del modelo comercial de la industria del ocio electrónico) de videojuegos basados en personajes y marcas protegidas por copyright con suficientes modificaciones como para evitar posibles denuncias o como simple recurso para atraer a potenciales consumidores. ${ }^{20}$

El nombre del personaje como (casi) único factor de unión con la obra sucede también en Aiming at Don Quixote (2016), del desarrollador independiente Yuki Fujimoto, un juego de acción y puntería con gráficos retro en el que controlamos los movimientos de un caballero con una lanza roja que debe llegar hasta el molino esquivando burros (que definen también las paredes que limitan la zona de juego). E1 hecho es curioso, porque, aunque usa ese nombre en su versión occidental, el juego en todos sus elementos internos de presentación, como los menús, se denomina The Legend of Pipin: mantiene el burro, el caballero con lanza roja y el molino, pero el nombre de don Quijote no aparece en ningún lado $\mathrm{y}$, de hecho, solo en el manual de instrucciones integrado nos cuenta que «Pipin is a boy who lives in a small village. Pipin has a dream to become a famous knight like Don Quixote! "I will be a famous knight!!" Pipin decide that he challenge to a windmill in his village $[\mathrm{sic}] »$.

De forma similar, se lanzó en 1994 Don Quixote: A Dream of Seven Crystals, que apostaba por el rol con una elevada cantidad de secuencia animadas: en esta ocasión se lanzó en LaserActive, un dispositivo modular de Pioneer que podía ejecutar juegos de Mega Drive y TurboGrafx I6 en cartucho y CD-ROM, además

20 Así, nos podemos encontrar con personajes y sagas que lograron triunfar y convertirse en propiedades intelectuales bien definidas que nacen con una clara inspiración en personajes de cine, cómic, etc., como en el caso del cinematográfico Indiana Jones, germen del videojuego español Fred (I983) para ZX Spectrum, un aventurero que recorre tumbas y ruinas buscando tesoros. Más recientemente, el personaje de Lara Croft de la saga Tomb Raider (I996) nace a la sombra de Jones, y hay rasgos de ella y de Indiana Jones en el germen de la saga Uncharted: Drake's Fortune (2007) y su personaje principal, el cazador de tesoros Nathan Drake. 
de títulos propios en Laserdisc, como este. ${ }^{21}$ En este juego se nos cuenta que la princesa Dulcinea ha sido secuestrada por un usurpador que quiere conquistar su reino, pero antes debe encontrar siete bolas mágicas de cristal. Don Quijote asume la misión de rescatarla y para ello se enfrenta a todo tipo de monstruos y criaturas fantásticas. Frente a esto, el juego se abre con unas secuencias aéreas de imagen real en las que vemos campos de La Mancha con, por supuesto, múltiples molinos e incluso alguna toma a vista de pájaro de Toledo. Cuando se inicia el juego se da paso al estilo habitual de dibujo animado de este tipo de producciones (se emplean fotografías y vídeos de Toledo en determinados momentos, como cambios de escena). La historia, evidentemente, no se basa en el texto de Cervantes, pero sí toma personajes clave y los reimagina en clave de fantasía medieval, con un Quijote canoso (pero fornido y no demasiado anciano) que asume la misión de rescatar el reino. Se convierte, de nuevo, en héroe de acción, una interpretación del personaje muy alejada del referente literario y que sirve apenas como excusa para plantear una aventura en la España del Medioevo.

En cuanto a las adaptaciones secundarias, no solo Dinamic partió de texto y producción audiovisual: esta estrategia se repitió con el videojuego Donkey Xote, basado en la película homónima (2007) que se basaba en la segunda parte de la novela. La película reinventaba el mundo ficcional cervantino desde el punto de vista de Rucio y presentaba a los espectadores una visión más próxima al personaje literario (se expone claramente que don Quijoteno está loco). La cinta se centra en los anhelos del asno,

2I El juego se ejecutaba en el Mega LD PAC creado por Pioneer y Sega con capacidad para leer discos propios Mega LD de 20 y $30 \mathrm{~cm}$, además de CD-ROM del accesorio Mega CD de Mega Drive.

quien anhela ser la montura del caballero y tomar el papel de Rocinante, que es retratado como un vago que odia dejar su establo. Sin embargo, el videojuego deja de lado estas cuestiones y nos pone en el papel de Rucio y Sancho, alternando entre ambos personajes, en una aventura de exploración donde la figura del propio don Quijote es quizá lo menos importante. Se respeta la iconografía clásica de los molinos y hay otros elementos estéticos identificables a través del imaginario visual diseñado para la película.

Más alejado de esta línea estética es el juego para navegadores Don Quixote (20II) — publicado en Kongregate y creado por un aficionado-,${ }^{22}$ que nos pone en el papel de un personaje que no se parece en nada a la imagen icónica del personaje cervantino en mitad de un entorno más selvático que manchego, de nuevo con la misión de rescatar a una princesa, volviendo al retrato de don Quijote como personaje heroico y aventurero.

Por otro lado, don Quijote ha hecho también apariciones en forma de cameo en otros videojuegos, es decir, títulos que no se centran en la obra de Cervantes ni pretenden recrear su universo ficcional, pero que sí han utilizado alguno de sus elementos para secuencias concretas. Un caso especialmente relevante es el de Maldita Castilla (20I2) del estudio español Locomalito. ${ }^{23}$

22 Título desarrollado sobre la tecnología de Unity para navegadores. Los cambios en los parámetros de gestión de plugins de terceros en los principales navegadores hace que el juego no sea compatible en ordenadores actuales que no cuenten con un navegador sensiblemente desactualizado.

23 Estudio y seudónimo del desarrollador malagueño Juan Antonio Becerra. Este juego fue creado en colaboración con Gryzor87 (música y efectos de audio), con manual diseñado por Jacobo García e ilustraciones promocionales de Marek Barej. El título se distribuye gratuitamente (freeware) en su versión para ordenador, lanzada en 2012. En 2016 debuta en consolas, en formato comercial, con 
En cuanto a las referencias literarias, resulta innegable que hay múltiples guiños a la figura del héroe caballeresco y que el folclore español está presente, aunque tomando elementos de toda la geografía (no se restringe a Castilla) e incluso criaturas de tono más genérico, como ciertos tipos de espectros o los zombis.

$\mathrm{El}$ tercer jefe final del juego es Quijote loco (Crazy Quixote) ${ }^{24}$ que tiene una apariencia metálica completa (incluyendo su rostro), casi como si fuera un autómata, al que nos enfrentamos en una biblioteca en llamas. No es casualidad que en los momentos previos a este enfrentamiento podamos rescatar una copia de El Amadís de Gaula de las llamas. Se logra evocar así no solo la locura del hidalgo y el célebre pasaje de la quema de libros, sino también rescatar y rendir tributo a Amadís y su texto, de especial relevancia en el mundo libresco de la obra de Cervantes.

De hecho, la figura de don Quijote (y la asociación de su autor con la identidad cultural española) es tan fuerte que no debe extrañarnos que haya multitud de guiños a escritor y personaje en los videojuegos, aunque algunas sean

la versión revisada Maldita Castilla EX publicada por Abylight Studios. Nosotros nos centramos en la versión original para ordenador

${ }^{24}$ Los (escasos) textos del juego están en inglés, pero los nombres de los enemigos y otros elementos del juego aparecen en castellano en el manual de instrucciones. Solo unos pocos enemigos son omitidos, sin duda para reservar algunas sorpresas para el jugador. El manual, a su vez, incorpora ilustraciones inspiradas en los grabados de los manuscritos medievales y algunos arcaísmos y tipografía gótica (inspirada en la letra Textualis). Veamos, como ejemplo, la descripción de las serpientes: «Adán hizo bien al sospechar destas hideputas, cuya mordedura supone el adiós a este mundo» (Locomalito, 2012: 13). Por tanto, la presencia quijotesca es realmente anacrónica - la estética caballeresca, dentro de la fantasía medieval, se corresponde más bien con la Alta Edad Media, situando al juego más bien en ese periodo y, por tanto, lejos todavía de los primeros compases del siglo XVII que vio nacer al personaje de Cervantes-. muy circunstanciales: así, por ejemplo, en la saga de lucha con espadas Soul Calibur ${ }^{25}$ tenemos al pirata español Cervantes de León. También abundan los personajes quijotescos, como en driculada (2015), protagonizado por un noble que ha enloquecido y está atrapado en su propia mente, dominado por su visión ficcionalizante del mundo. ${ }^{26}$ De hecho, si tenemos en consideración los personajes quijotescos y sanchescos, estos son probablemente tan abundantes como en cualquier otro medio narrativo, pues el arquetipo de esta pareja está tan extendido como su dinámica de quijotización y sanchificación.

\section{JUEGOS SERIOS Y EDUCATIVOS EN TORNO A DON QUIJOTE}

En la línea de títulos considerados juegos serios ${ }^{27}$ nos encontramos con una aplicación para dispositivos móviles que adapta la obra de Cervantes con una estética propia de la literatura infantil, en la medida en que el texto se reduce sensiblemente, se acompaña de grandes ilustraciones con elementos interactivos y redefine la idea de libro adaptado al lector infantil y juvenil gracias a las posibilidades de interacción del dispositivo electrónico. Se trata de la edición de Touch of Classic de la obra de Cervantes publicada en 2012 bajo el nombre de Las aventuras de

25 El personaje debuta ya en la primera entrega de la saga, que fue conocida como Soul Edge y que debutó en recreativas en 1996.

26 Arturo Monedero, uno de los creadores del videojuego, reconoció abiertamente la inspiración en la obra de Cervantes (Maeso, 2015).

27 Esta etiqueta se emplea para complementar el concepto del entretenimiento educativo o edutainment (educación entretenida), pues son empleados con una función instruccional. Los juegos serios son aquellos en los que el propósito educativo es explícito y no están diseñados para ser jugados por mera diversión. 
Don Quijote. ${ }^{28} \mathrm{El}$ texto fue adaptado por Ana Herrera y cuenta con ilustraciones de Miguel Calero y estaba disponible en español e inglés, incluyendo los textos y la voz del narrador. La interacción del lector permite, sobre todo, sacar a la luz el contraste entre la realidad y la percepción del caballero, dando lugar a un contraste de fantasía y realidad que transmite con acierto la locura de don Quijote. Hay elementos interactivos que inician pequeñas animaciones y emblemas escondidos en las ilustraciones que debemos buscar, aportando un elemento lúdico definitivo. Así, por ejemplo, podemos tocar en la cabeza de Alonso Quijano mientras lee un libro de caballerías para ver cómo aparece un globo de pensamiento repleto de criaturas y caballeros. $\mathrm{O}$, cuando está ante el espejo con sus calzones, podemos coger las partes de la armadura que están amontonadas en el suelo y arrastrarlas hasta el personaje para equiparlo: al terminar, en el espejo - hasta entonces sin reflejo- aparece un vigoroso joven pelirrojo con armadura dorada y pose heroica: se inicia la disociación de la realidad del personaje y se refleja en la interacción y en el retrato doble Alonso Quijano frente a don Quijote.

No se trata tanto de crear un ebook, sino de unificar elementos lúdicos con otros de lectura con cierto grado de interacción y crear una nueva versión de la obra. El terreno de las aplicaciones que se sitúan estrictamente en el terreno de las versiones infantiles convertidas en libro ilustrado para dispositivos móviles con un grado menor de interacción (e incluso ninguna) tiene una cantidad ingente de representantes.

${ }_{28}$ Aunque fue subvencionada por el Ministerio de Educación, Cultura y Deporte, la falta de actualizaciones ha hecho que la aplicación ya no esté disponible en la App Store de Apple al haber sido declarada obsoleta. El mismo destino han sufrido el resto de aplicaciones de Touch of Classic, incluyendo textos de Shakespeare, Shelley y otros escritores clásicos internacionales.

Entre ellas consideramos necesario destacar Las aventuras de Don Quijote de la Macha Interactivo (2013) por su integración de elementos que requieren que el lector actúe sobre la pantalla para que la historia pueda progresar, aunque, desde luego, no es un videojuego en el sentido estricto.

En 2012 se presenta el proyecto, impulsado desde el GILab de la Universitat de Girona, de diseñar un videojuego para recrear la obra de Cervantes (Sbert, 2014) ${ }^{29}$ con un elevado nivel de interacción al emplear los recursos completos de un videojuego contemporáneo utilizando tecnología como el motor Unity: ${ }^{30}$

The game objective is to introduce the Don Quixote's novel to the player. With this purpose the game will reproduce the adventures of Don Quixote's novel giving the player the chance to relive them in first person.

Following the novel structure we will consider the chapters independently, and for each chapter we will reproduce the narrated adventure in a realistic ${ }_{3} \mathrm{D}$ scenario where Don Quixote and Sancho Panza have to face different challenges (20I4: 4 )

El proyecto no se ha publicado, ${ }^{3 \mathrm{I}}$ por lo que no podemos valorar el tratamiento que se realiza. Sin embargo, el artículo del equipo respon-

29 Citamos el artículo científico del equipo que muestra el proyecto, pero las primeras noticias en prensa generalista se remontan, efectivamente, a dos años antes (UdG, 20I2).

$3^{\circ}$ Un motor de videojuego es un conjunto de rutinas y programas integrados para diseñar, crear y representar un videojuego. Esto incluye sistemas de objetos, animación, sonido, física, iluminación y efectos visuales, inteligencia artificial y demás componentes necesarios.

${ }^{3}$ D Durante un tiempo hubo disponible una demo descargable en línea <http://gilabparc.udg.edu/jocs/quijote/demo.html> [15-03-20I7] pero no se encuentra ya en el servidor. Sí podemos ver todavía en teaser que muestra la línea estética del proyecto: <https://www.youtube.com/ watch?v=yr4UBDYIT $5 A>\left[\mathrm{I}_{5}-\mathrm{O}_{3}-2017\right]$. 
sable antes citado sí señala el objetivo de permitir una aproximación a la obra de Cervantes, fiel a la misma, con elementos lúdicos dedicados a estimular al jugador. Se explicaba en la nota de prensa publicada en diciembre de 2012 que:

En aquest joc, en què el participant controla diversos personatges com el mateix Don Quijote i Sancho Panza, recrearà diverses aventures que se succeeixen al llarg de l'obra. En concret, el videojoc farà especial èmfasi en el capítol vuitè de la novel·la, el qual relata la famosa trobada entre el cavaller i els molins de vent. (UdG, 2012)

Se trata, por tanto, de un proyecto mucho más vinculado al juego de Dinamic de 1987 (con el capítulo de los molinos como pilar fundamental para definir objetivos e identidad del proyecto tomando como referente el celebérrimo capítulo de la obra original) que a otros usos de la figura de don Quijote, donde se ha optado - como hemos visto - por una reconversión completa del personaje y su mundo ficcional para convertirlo en un avatar más de la heroicidad de la fantasía medieval.

\section{EL QUIJOTE DOMINANTE EN LOS VIDEOJUEGOS}

Don Quijote ha sido - como hemos vistoprotagonista de aventuras conversacionales, de aventuras de fantasía e incluso enemigo final, además de ser filtrado por el proceso de reconversión habitual de las adaptaciones de clásicos literarios a la literatura infantil añadiendo los elementos de interacción previsibles en tabletas y móviles. La presencia quijotesca se divide, por tanto, en dos grandes bloques de construcción de presencia en cuanto al entretenimiento electrónico: las aplicaciones de lectura con elementos interactivos y los videojuegos tradicionales, con sus diferentes géneros y categorías.
Así pues, es evidente que el peso de la figura quijotesca como ítem cultural dentro del sector del ocio electrónico es moderado en relación con otros mitemas y personajes literarios, en particular algunos escogidos como el ciclo artúrico y sus personajes principales. Su presencia directa no es tan potente como la de Lanzarote o Arturo, pero hay que admitir que personajes emblemáticos como Hamlet tampoco se han prodigado en exceso (cuestión aparte es la ingente cantidad de referencias al teatro de Shakespeare que inundan los guiones de cientos de videojuegos).

En cuanto al ciclo artúrico, este forma parte de la cultura popular mundial con suficiente peso como para integrarse incluso en un videojuego de la mascota de Sega, Sonic and the Black Knight (2009), en el que varios de los personajes artúricos se funden con los del mundo del erizo azul: Lanzarote del Lago es Shadow the Hedgehog, Galahad es Silver the Hedgehog, Gawain es Knuckles the Echidna, etc., e incluso aparece la Dama del Lago (que es Amy Rose). Este tipo de cruce entre mundos es lo suficientemente común como para no considerarlo una excentricidad, pero sí cabe preguntarnos si hubiera sido posible realizar un proyecto similar (y esperar que tuviera el impacto necesario en el mercado internacional) con otros mitos medievales. El peso de la cultura anglosajona y la difusión del ciclo artúrico a través de todo tipo de producciones de la cultura pop han ayudado a forjar un ítem cultural fácilmente reconocible y exportable que trasciende su peso específico como conjunto de leyendas fundacionales. ${ }^{32}$

32 Otros personajes de leyenda, como Robin Hood, han tenido también una fuerte difusión e internacionalización con presencia en videojuegos a través de versiones propias inspiradas en el material original o bien en alguna de las adaptaciones al cine. 
Sin embargo, en el caso de Don Quijote, su presencia está mucho más ligada a una visión alejada por completo de su concepción original: son predominantes cuantitativamente las apariciones del personaje como protagonista en títulos que sí toman algunos referentes muy populares (los molinos, el propio Sancho...) pero que se alejan por completo de la obra original y nos presentan un videojuego que bien podría estar protagonizado por cualquier caballero de Dungeon $\mathcal{E}^{\circ}$ Dragons. Don Quijote está atrapado, en muchos de estos videojuegos, en un universo de fantasía medieval como la que se criticaba tan duramente en las páginas de Cervantes-y en la propia creación de la obra一, situación irónica pero que nos muestra que la fama del personaje va mucho más allá del conocimiento sobre el protagonista cervantino, o del interés por retomar y explorar sus facetas y temas originales.

Así, Don Quijote es reinventado como héroe de acción con la aparente intención de aprovechar el reconocimiento de la marca: son juegos que podrían haber sido perfectamente protagonizados por cualquier otro caballero medieval, tanto originario de la literatura fantástica tradicional (un Lanzarote) como del propio mundo de los videojuegos (un Dirk de Dragon's Lair): se convierte en espadachín, muchas veces joven o al menos ágil y fuerte, capaz de rescatar a princesas de toda suerte de peligros en la Alta Edad Media. No solo eso: Dulcinea, en estos juegos, es una princesa real dentro del mundo ficcional, no una deformación de la realidad a través de los ojos de Don Quijote. Don Quijote en estos videojuegos no es, en definitiva, Don Quijote, sino un reflejo profundamente deformado y alterado. $\mathrm{O}$ lo que es lo mismo, una recreación plena del personaje cervantino para llevarlo al arquetipo del héroe medieval con - en ocasiones - respeto marginal a la imagen creada en torno al personaje a través de las pinturas $\mathrm{y}$

grabados que han acompañado al texto o que se han convertido también en obras autónomas vertidas desde el libro hasta el medio pictórico o escultórico.

Los videojuegos que han respetado más la concepción original del personaje son, en definitiva, clara minoría: el título de Dinamic de r987 y el —-todavía inédito- juego serio se convierten en el catálogo que ha trasladado la obra de Cervantes buscando la fidelidad. El cambio de medio impone alteraciones fundamentales, pues se salta de la palabra escrita al mundo audiovisual e interactivo y eso implica una reescritura en cualquiera de los casos. El proceso de remediación consigue mantener, en estos pocos casos, la fidelidad con el personaje y a través de eso logran preservar (al menos parcialmente) el ethos de la novela.

\section{CONCLUSIONES}

Como mito universal que ha pasado a formar parte de nuestra cultura iconográfica, don Quijote está necesariamente presente en un medio que dialoga de manera tan clara con la literatura y la cultura como es el videojuego. Además, la larga tradición de las adaptaciones del personaje cervantino en la literatura para adultos y niños, así como en otras manifestaciones artísticas, ha servido como precedente a la reescritura del caballero en otros medios y contextos.

En este sentido, los videojuegos, en su mayoría, han optado por emplear quijotes muy desplazados del hipotexto cervantino: conservan solo rasgos generales de los personajes, o alguna aventura. En algunos casos, del hipotexto solo conservan el nombre - y este incluso con modificaciones-. Con ello logran evocar en el jugador el conocimiento inconsciente del ideologema quijotesco, y mantener una conexión ventajosa en lo que se refiere al marketing del 
producto, sin por ello tener que condicionar su universo narrativo al original de Cervantes.

Por tanto, podríamos concluir que lo que estas obras hacen es apelar a los elementos que conforman la percepción de don Quijote que ha quedado marcado en el contexto cultural colectivo, empleando un conocimiento superficial de la novela original pero suficiente para que sea reconocible por un público no necesariamente lector de Cervantes. Todo ello viene a demostrar que el mito o ideologema es más fuerte que la obra, y que don Quijote se ha convertido en un mito independiente del hipotexto que le dio vida. La idea del personaje trasciende la obra por completo y permite que sus saltos mediáticos se basen no solo en el hipotexto, sino también en productos ya de por sí derivativos del mismo (y, en algunos casos, ya de por sí muy distanciados de la obra original).

Sin embargo, es esta capacidad del mito de resistir la desaparición a pesar de las reescrituras desplazadas las que demuestran la fuerza del icono quijotesco, y sus posibilidades de reescritura las que explican su permanencia a través de los siglos y los distintos soportes. En concreto, es lo que este mito aporta al juego de la remediación y la semionáutica: la posibilidad de emplear elementos sencillos del hipotexto y remezclarlos con elementos de otras narraciones y universos textuales.

RECIBIDO EN JULIO DE 2017

ACEPTADO EN JULIO DE 2017 VERSIÓN FINAL DE OCTUBRE DE 2017

\section{BIBLIOGRAFÍA}

Austen, Jane y Seth Grahame-Smith (2009): Pride and Prejudice and Zombies, Nueva York: Quirk Books.

Avalle-Arce, Juan B. (1989): «Quijotes y quijotismos del inglés», Ojáncano, 2, 58-66.
Borham-Puyal, Miriam (2015a): «Learning with Don Quixote for Children: the Presence of the Knight in Interactive Classrooms", Caracteres. Estudios culturales y críticos en la esfera digital, 4/I, IO5-I27.

Borham-Puyal, Miriam (20I5b): Quijotes con enaguas. Encrucijada de géneros en el siglo XVIII británico, Valencia: JPM Ediciones.

Borham-Puyal, Miriam (2016): «For the Amusement of His Merry Little Subjects: How British Children Met Don Quixote in the Long Eighteenth Century», Anales Cervantinos, XLVII, I79-204.

Bourriaud, Nicolas (2005): Postproduction. Culture as screenplay: How art reprograms the world. Nueva York: Lukas \& Sterling.

Canavaggio, Jean (2005): Don Quichotte, du livre au mythe: quatre siècles d'errance, París: Fayard, D.L.

CVG (I985): «The Don to the Rescue Computer and Videogames», CVG, 39, 39.

Fernández Porta, Eloy (2008): Homo Sampler. Tiempo y consumo en la Era Afterpop, Barcelona: Anagrama.

Ferré, Juan Francisco (2007): «La literatura del post. Instrucciones para leer narrativa española de última generación», en J. Ortega y J. F. Ferré (eds.), Mutantes. Narrativa española de última generación, Córdoba: Berenice, 7-21.

Gutiérrez Párraga, María Teresa (2006): La significación del juego en el Arte Moderno y sus implicaciones en la educación artística, Madrid: UCM [tesis no publicada].

Iffland, James (I987): «On the Social Destiny of 'Don Quixote': Literature and Ideological Interpellation: Part I", The Journal of the Midwest Modern Language Association, 20/1, I7-36.

Maeso, Gustavo (2015): "Los Delirios de Von Sottendorff, de Bilbao a la galaxia Nintendo", $E l$ Mundo, I2 de diciembre, $\leq$ http://www.elmundo. es/tecnologia/2015/I2/I2/566bigc > [consulta: I-III-2OI7].

Martín García, Jorge (2015): «Luchar con odres: reescritura cervantina y subversión en el videojuego Don Quijote (1987)», Caracteres. Estudios culturales $y$ criticos de la esfera digital, $4 / \mathrm{I}, 83-\mathrm{IO} 4$.

Maruo, Kosuke, et al. (2009) [2016]. Don Quijote de la Mancha: el manga, trad. Marta Estefanía Gallego Urbiola, Madrid: La Otra H.

Mora, Vicente Luis (20I4): «Acercamiento al problema terminológico de la narratividad transmedia», Caracteres. Estudios culturales y críticos de la esfera digital, 3/I, II-4I. 
Pardo, P. J. (20II): «Cine, literatura y mito: Don Quijote en el cine, más allá de la adaptación», $A R B O R$ Ciencia, Pensamiento y Cultura, 187/748, 237-246.

Riera Muñoz, Pau Damià (2013): «Narrativa, música y transmedia en Nier: hacia una nueva obra de arte total», Caracteres. Estudios culturales y críticos de la esfera digital, 2/I, 169-186.

Sbert, Mateu, et al. (20I4): "A game to relive Don Quixote's adventures», I Congreso de la Sociedad Española para las Ciencias del Videojuego, <http:// gaia.fdi.ucm.es/sites/cosecivir//es/papers/ı6.pdf> [consulta: I-III-20I7].

Universitat de Girona (2012): «El GILab desenvoluparà un nou videojoc educatiu basat en la història d'E1 Quixot», Universitat de Girona - Archivo de Noticias, <http:// www.udg.edu/Not\% $\mathrm{C}_{3} \%$ A D ciesiagenda/ Reculldenot\%C3\%ADcies/tabid/2575/p/2849I/ language/es-ES/Default.aspx> [consulta: $\mathrm{I}-\mathrm{III}-$ 20I7].

Watt, Ian (1996): Myths of Modern Individualism, Cambridge: Cambridge University Press.

\section{LUDOGRAFÍA}

Cinematronics (1983): Dragon's Lair, EE. UU.: Cinematronics.

Delirium Studios (2015): Los Delirios de Von Sottendorff y su Mente Cuadriculada, España: Delirium Studios.

Fujimoto, Yuki (20I6): Aiming at Don Quixote, Japón: Two Cats.
Hoey, Charlie y Pete Smith (2011): The Great Gatsby, EE. UU.: Hoey \& Smith.

id Software (I992): Wolfenstein 3D, EE. UU.: Apogee Software.

Indescomp (1983): Fred, España: Indescomp.

KidzPlayMob (2013): Las aventuras de Don Quijote de la Macha Interactivo, España: KidzPlayMob.

Locomalito (2012): Maldita Castilla, España: Locomalito.

Menéndez, Paco (1987): La abadia del crimen, España: Opera Soft.

Naughty Dog (2007): Uncharted: Drake's Fortune, EE. UU.: Sony Computer Entertainment.

Oberon Media (2010): Classic Adventures: The Great Gatsby, EE. UU.: I-Play.

Pioneer LDC (1994): Don Quixote: A Dream of Seven Crystals. EE. UU.: Pioneer / SEGA.

Revistronic Madrid (2007): Donkey Xote, España: Filmax.

Sonic Team (2009): Sonic and the Black Knight, Japón: SEGA.

Square B Team (1989): Square’s Tom Sawyer, Japón: SquareSoft.

Touch of Classic (2012): Las aventuras de Don Quijote, España: Touch of Classic.

Trillium (I984): Fabrenheit 45I, EE. UU.: Trillium.

Universal Co. (1984): Super Don Quix-ote, EE. UU.: Universal.

Visceral Games (2010): Dante's Inferno, EE. UU.: Electronic Arts.

Winkysoft (1989): The Adventures of Tom Sawyer, Japón: SETA. 